\title{
Corpo-imagem: o jogo do ator na cena intermedial
}

\author{
Corps-image: le jeu de l'acteur dans \\ la scène intérmediale
}

\section{Gabriela Lírio Gurgel Monteiro}

Gabriela Lírio Gurgel Monteiro Professora associada do curso de Direção Teatral da Escola de Comunicação da Universidade Federal do Rio de Janeiro (UFRJ)

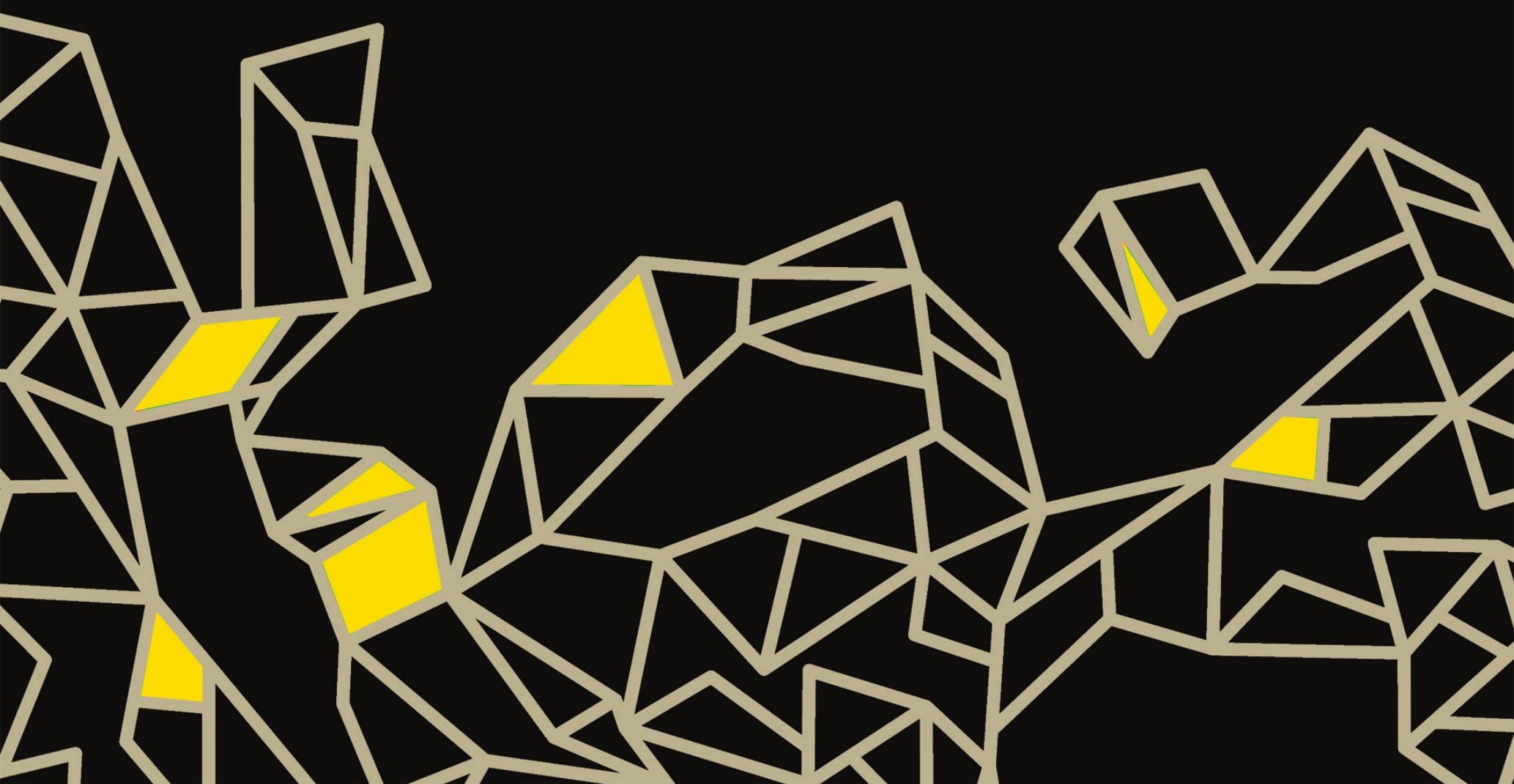




\section{Resumo}

Este artigo analisa o jogo do ator na cena intermedial e a problemática da sensibilidade da imagem. Com o advento das tecnologias digitais, o teatro contemporâneo investe nos relatos autobiográficos e na interface entre o ator e as imagens, criadas e/ou pré-registradas e projetadas na cena.

Palavras-chave: Ator, Imagem, Intermedialidade.

\section{Résumé}

Cet article analyse le jeu de l'acteur dans la scène intérmediale et la problématique de la sensibilité de l'image. Après le développement des technologiques numériques, le théâtre contemporain a investi dans les rapports autobiographiques et dans l'interface entre l'acteur et les images - créées et/ou préenregistrés - et projetées sur la scène.

Mots-clés: Acteur, Image, Intermédialité

A partir dos anos 1990, vemos a emergência do uso de dispositivos nas artes da cena e o surgimento de novos processos de criação e de recepção interativos. Com o advento do digital, o corpo do ator adquire outras funções, tendo sua percepção radicalmente modificada pelo uso de tecnologias da cena. Segundo Couchot (2007, p. 216, tradução minha), estamos diante de uma nova matriz perceptual "associada a uma nova corporeidade, um híbrido de carne e cálculo". Em espetáculos intermediais, a interação entre corpo virtual e corpo em carne e osso redimensiona o processo de criação do artista, que busca novas estratégias para se relacionar com imagens projetadas em tempo real e/ou pré-gravadas. Atravessado por imagens intermediais, o corpo do ator é expandido, não apresenta limites delineados; reinventa-se a todo momento, porque não fixa uma única forma. Em constante transformação, é corpo-imagem, multissensorial e fractal.

De que modo perceber/investigar o corpo em um espetáculo ou performance que utiliza imagens digitais? Sendo esta uma questão primordial das pesquisas intermediais, induz à reflexão sobre técnicas, tipos de processo de criação, interfaces possíveis entre o jogo do ator e as imagens projetadas. A introdução de dispositivos na cena - câmeras, projetores, softwares, suportes de diferentes materialidades - interfere diretamente na percepção corporal, ao 
provocar a hibridização entre orgânico e tecnológico. O uso do dispositivo é decisivo para uma mudança significativa no modo de atuação, mesmo quando não é percebido em sua materialidade, quando não está visível na cena ou quando é parte apenas dos ensaios e do processo criativo.

A relação entre corpo e dispositivo pode ser analisada a partir de dois axes não excludentes: o temporal (ligado à duração da imagem em sua inter-relação com o ator) e o espacial (ligado à materialidade da superfície na qual se dá a interação entre ator e imagem). Nesta análise, interessa-me investigar dois tipos de dispositivos: a tela de projeção e o uso da câmera na cena intermedial. Ambos estão conectados e sujeitos a variações decorrentes de seus usos.

As telas de projeção variam em tamanho e número. Podem ser reduzidas, como as pequenas telas de TV utilizadas em vários espetáculos, como as do Wooster Group a cicloramas que tomam todo o palco (como fazem Lepage, Lemieux-Pillon etc.); variam entre uma e várias dispostas pelo espaço cênico (a exemplo de Ivo Van Hove, Cassiers, Pitoiset, Studio Azzurro). Apresentam também diferenças com relação às texturas e tipos de superfícies, sendo comumente substituídas por objetos (cubos, painéis, cortinas etc.) e materiais diversos (tecidos, vidros, madeira, plástico etc.). O corpo igualmente pode servir como suporte de imagens, um corpo-tela. Nesse caso, a imagem, geralmente, está intimamente condicionada às ações físicas que, muitas vezes, são limitadas devido às dificuldades impostas por uma projeção em movimento. Em Os cegos (2002), de Denis Marleau, o diretor cria o que denomina "fantasmagoria tecnológica", radicalizando a pesquisa na projeção dos rostos dos atores em máscaras cenográficas, mas sem a presença deles na cena.

\section{Denis Marleau e o duplo fantasmagórico}

Em Os cegos, da obra de Maurice Maerterlinck, Marleau utiliza a tecnologia para criar doze rostos, seis masculinos, seis femininos, que surgem em um palco completamente às escuras. São cegos, imóveis e conversam de modo a verificar se estão mesmo vivos. A escolha do uso de máscaras digitais projetadas em cena propiciou desvencilhar o ator da personagem, o que redelimitou as pesquisas sobre o simbolismo no teatro e o interesse de 
Marleau pela morte - tema que atravessa todo teatro ocidental e oriental e é retomado pelo diretor por meio da análise crítica das obras de Artaud e Kantor.

Não é o mundo paralelo que existe na tela plana do cinema onde tudo é possível, mas sim o de presenças reais e frágeis que falam entre elas de sua própria condição ambígua e paradoxal, desta angústia de existir ou não, de não ver, de não compreender e de ter medo de morrer. (MARLEAU, 2010, p. 58, tradução minha)

A especificidade do espetáculo refere-se à ausência dos atores, criada por meio de uma "fantasmagoria tecnológica" que buscou reproduzir as personagens por meio do uso da ilusão de ótica, dialogando diretamente com a ideia do "teatro de andróides", de Maeterlink. O diretor optou por ser fiel à máxima desse dramaturgo ao substituir o ator por uma sombra ou projeção de formas simbólicas. Para isso, criou doze máscaras em relevo sobre as quais projetou o rosto de dois atores, um homem e uma mulher, com o objetivo de criar um efeito de presença que provocasse "um tipo de dúvida imanente sobre o palco, de fazer surgir o invisível” (Ibid., p. 59, tradução minha).

O efeito obtido é surpreendente porque o público demora a perceber que há apenas dois atores, e não doze, assim como fica a dúvida sobre serem atores de verdade em cena ou projeção de rostos. Marleau privilegiou as escalas um pouco maiores que a dimensão do rosto humano com o objetivo de tecnicamente alcançar a vida, sem contudo mostrá-la, como defendia Maerterlink.

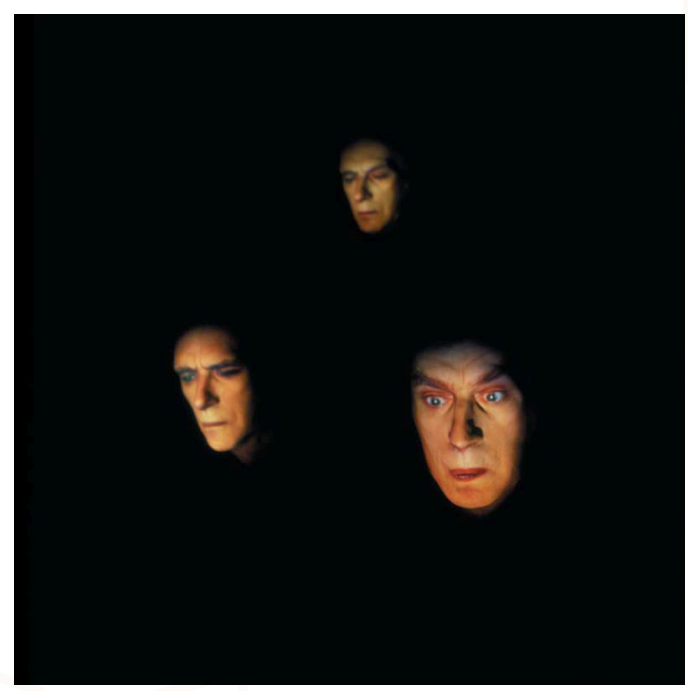

Figura 1 - Máscara em Les aveugles, de Denis Marleau.

Foto: Richard-Max Trembley 
Interessado pelas possibilidades e qualidades plásticas advindas do uso da tecnologia e influenciado pelas obras de Janet Cardiff, Bill Viola, Gary Hell e Tony Ousler, Marleau busca integrar dispositivos à dramaturgia. Para ele, interessa o estudo da presença do ator, no qual o foco é a experiência do sensível e do presente, seja através de uma imagem projetada do ator ou da ligação de seu corpo com seu duplo digital. "Que ele se transforme, ele mesmo, em uma espécie de tela onde o espectador se projete, por meio do qual se sente absorvido" (Ibid., p. 50, tradução minha).

Tanto em Os cegos como no espetáculo anterior, Os três últimos dias de Fernando Pessoa (1998), Marleau investiga um processo de direção de atores complexo devido à resistência de alguns deles ao processo de criação, no qual a presença é adquirida por meio da relação direta com a imagem projetada. A dificuldade reside na imobilidade quase total do ator, a fim de que a imagem não saia dos limites da máscara e "seu rosto não se transforme na obra de Francis Bacon" (Ibid., p. 53, tradução minha), o que revela a precisão do trabalho. Interessante observar que a noção de presença é multiplicada por uma espécie de concentração. Diante da imobilidade, há uma lente de aumento em cada palavra emitida, no timbre do ator e no encadeamento das frases, em cada mínima expressão facial.

\section{Imagens digitais e os diferentes tipos de tela: o jogo do ator em tempo real}

As diferenças de uso das telas em um espetáculo ou performance intermedial levam a uma constante mudança de percepção por parte do espectador, que busca reunir sentidos através da captura de imagens em escalas variadas. Poderíamos supor que tais diferenças, ao se reproduzirem, provocam um efeito de distanciamento, uma vez que denotam a fragmentação e/ ou a não linearidade nos modos de apresentação da imagem. Em contrapartida, no processo de recepção, a flutuação do olhar em direção ao reconhecimento de um espaço heterogêneo e à apreensão fragmentária das imagens, decorrente das variações de escala, pode fazer emergir um tipo de percepção fractal, que leva a um estado sensorial de absorção das imagens. A heterogeneidade espacial, formada por meio da articulação entre as imagens virtuais e 
os limites espaciais dados pela disposição física das superfícies de projeção, corrobora para o aparecimento de novos processos de recepção. A não especificidade da tela, que pode adquirir qualquer forma em cena, nos leva a crer que "a imagem não pertence mais à tela, é exatamente o contrário: a imagem produz a tela, ela concede-lhe esta função"(CHATONSKY, 2008, p. 94, tradução minha). A imagem adquire, portanto, autonomia e provoca a ruptura com os limites materiais do próprio dispositivo.

Manovich, analisando uma genealogia possível da tela, reporta-se à interatividade como elemento primordial da imagem em tempo real, ao estabelecer relação com o presente, diferentemente de uma tela clássica que "mostra uma imagem estática, permanente" ou de uma tela dinâmica que "mostra uma imagem em movimento do passado" (MANOVICH, 2010, p. 214, tradução minha). A partir dessa afirmação, defendo que o uso de imagens em espetáculos intermediais complexifica a noção de espaço cênico, transformando a tela em uma "janela", na qual o fora de campo (hors-champs), ou seja, aquilo que não é visível pelo enquadramento da cenografia teatral, colabora na composição da dramaturgia de imagens, assumindo funções ligadas:

- à memória - espetáculos autobiográficos ou documentais. Neste caso, as imagens-referências relacionam-se ao passado, ainda que este seja presentificado em cena;

- à percepção - por meio de referências picturais, fotográficas ou cinematográficas de uma tela clássica que ora compõem o imaginário do ator, ora apontam para um espaço exterior à cena, podendo se transfigurar em paisagens;

- à transmutação do corpo do ator que, em tempo real, dialoga consigo mesmo e/ou com seu duplo digital por meio de uma tela interativa. Trata-se, em muitos casos, de um corpo híbrido. Nos espetáculos imersivos, a interação ocorre, ainda, entre imagem e espectador, que se apresenta como operador/agente de uma transformação permanente.

A delimitação das funções desempenhadas pelas telas em espetáculos intermediais não visa à criação de regras ou metodologias específicas para seu uso, uma vez que há para elas inúmeras possibilidades, tantas quantos são os processos de criação implicados. É preciso atentar para um agenciamento 
complexo. Isso significa que, em um mesmo espetáculo, pode-se observar usos distintos de uma mesma tela ou, ainda, variações de diferentes tipos. $\mathrm{O}$ que qualifica de forma diferenciada seu uso na cena intermedial são "ligação e corte simultâneos entre dois espaços: o virtual, o da imagem; e o atual, o lugar de sua exposição" (BUSTROS; AURTENÈCHE, 2008, p. 77, tradução minha). A especificidade do uso do dispositivo na cena intermedial contemporânea é dada por meio do corte e/ou da ligação entre os dois espaços, construídos a partir da interação entre as ações físicas do ator e as imagens digitais. Por outro lado, não podemos deixar de notar a existência de um uso meramente decorativo, revelado quando há a ausência de interatividade, ou seja, quando a imagem é meramente "pano de fundo".

$\mathrm{Na}$ cena intermedial, identifico alguns elementos importantes constitutivos do jogo cênico: os limites espaciais, definidos pelas telas com seus espaços dentro de campo e fora de campo, e sua possível ruptura; o enquadramento das imagens (tipos de planos, profundidade de campo), a montagem (continuidade e/ou descontinuidade) e sua relação com a dramaturgia; a pesquisa sobre a distância tomada pelo corpo do ator em relação às imagens projetadas; e o trompe l'oeil, decorrente da fusão entre corpo e imagem. O jogo do ator não é mais voltado apenas para a plateia e seus parceiros de cena, mas também para as imagens virtuais. Há, portanto, uma evidente modificação da percepção do espaço, uma vez que este é ampliado e atravessado pelo espaço virtual, tornando-se híbrido - além da modificação do tempo de jogo (em muitos casos, bastante preciso devido à interação com as imagens), da percepção de si e dos demais atores, que veem e reagem aos limites das transformações de seus corpos (reduzidos, aumentados, delimitados através de planos, cortes e enquadramentos). Isso ocorre, por exemplo, diante de um close, em que não percebemos mais o espaço em sua totalidade, provocando uma sensação de abolição espacial.

\section{A floresta que anda - imersão no espaço cênico expandido}

O modo como ator se relaciona com o duplo de si projetado é questão recorrente em diversos espetáculos contemporâneos. Nas artes imersivas 
interativas, os limites do corpo não são mais definidos. Segundo Couchot (2015, p. 9, tradução minha), esse tipo de obra de arte provoca uma ruptura com as artes não interativas porque "coloca em ação os processos mentais pré-motores, sensório-motores e cognitivos que não são habitualmente presentes de forma tão intensa na situação de recepção". O corpo adquire, portanto, um outro status.

\begin{abstract}
O espaço da instalação é o da promiscuidade, portanto, do transbordamento sensível. O corpo se confunde e é confundido [...]. Como se chega a essa confusão? O que significa esta referência constante ao corpo? O que pode implicar esta distinção feita entre o sensível e o físico? (WEBER, 2003, p. 70, tradução minha)
\end{abstract}

Com o uso da tecnologia 3D, o espaço cênico é ampliado e, em alguns casos, transforma-se em uma grande tela para projeção de imagens, em que identificamos a expansão da superfície da tela, como no caso do espetáculo Chroma, de Shiro Takatani, no qual as imagens em 3D são projetadas no fundo da cena, no chão e no corpo do ator. Entre o sensível e o físico perde-se, às vezes, a noção de delimitação espacial. No espetáculo imersivo $A$ floresta que anda (2015/2016), a diretora Christiane Jatahy cria uma cena intermedial e expandida, na fronteira entre teatro, cinema, performance e artes visuais. Podemos analisar o espetáculo como uma instalação, em seu caráter documental, como teatro e também como performance. Inspirada na personagem Macbeth, de Shakespeare, Jatahy discute o poder político de manipulação e subjugação dos sujeitos. Para isso, coloca em cena quatro telas, mostrando um documentário diferente em cada. O primeiro apresenta Próspero, 28 anos, refugiado do Congo, que mora em São Paulo. Ele teve sua família foi assassinada, foi preso e torturado em seu país. O segundo documentário apresenta Michelle, moradora da Rocinha, a maior favela da América do Sul, no Rio de Janeiro. Seu tio foi assassinado pela polícia militar. O terceiro revela Igor, um estudante carioca, que foi preso por participar das manifestações de 2013. E o quarto filme apresenta um habitante de Brasília pertencente ao movimento dos sem-teto.

O público é convidado a percorrer o espaço e a assistir, da forma que the convém, aos documentários. A atriz Julia Bernat, sentada em uma cadeira no bar, é presença bastante teatral. Segundo Jatahy, ela representa Lady Macbeth. 
No fundo do bar, há um grande espelho. Os espectadores podem beber algo e se ver no espelho, mas não sabem que uma câmera está escondida atrás dele e que há outras câmeras distribuídas pelo espaço'. Sem saber, os espectadores são filmados e seus rostos, em alguns momentos, projetados nos documentários como imagens fantasmagóricas, diluindo a fronteira entre a imagem ficcional e a documental, invertendo seus espaços (o documentário passa a ser uma ficção com a projeção do rosto do espectador, que se torna ele mesmo objeto ficcional da imagem documental antes projetada). No ambiente imersivo proposto por Jatahy, os espetadores se misturam às imagens projetadas em tempo real. Tornam-se imagem. Jatahy investiga os limites entre o corpo em carne e osso do espectador e o corpo virtual com o objetivo, talvez, de buscar uma forma em transição, uma imagem híbrida na experiência cênica.

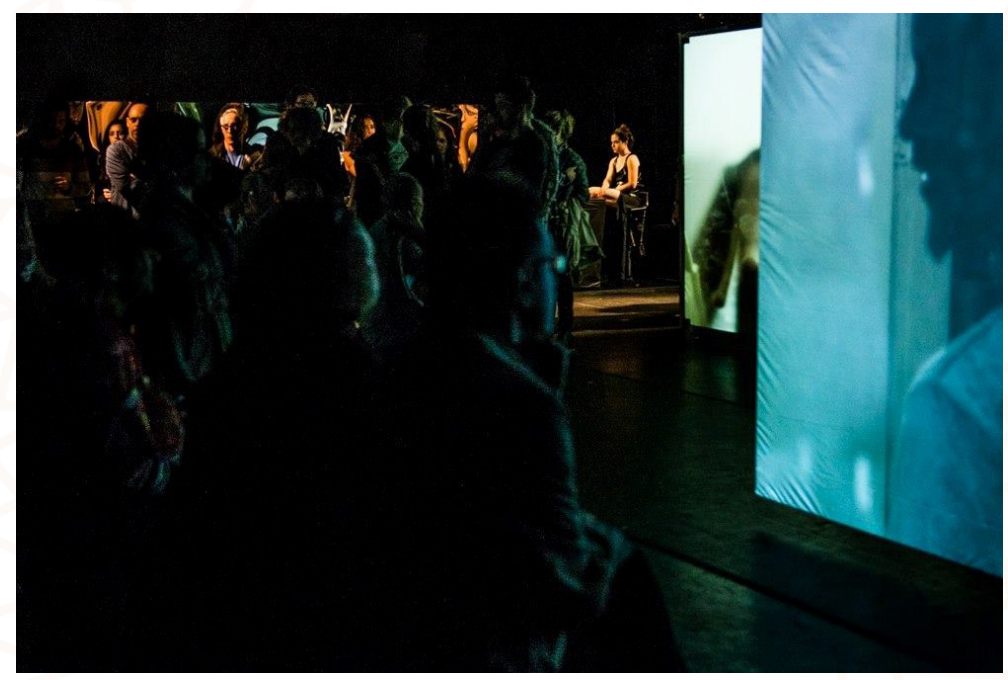

Figura 2 - As múltiplas telas de A Floresta que anda, de Christiane Jatahy. Foto: divulgação do espetáculo.

Retirada do site: http://christianejatahy.com.br/project/a-floresta-que-anda

Ao final do espetáculo, as quatro telas se unem, transformando-se em um grande telão, caminhando em direção aos espectadores e projetando em tempo real suas imagens. Compõe-se a imagem de uma floresta tecnológica de pessoas que, inertes, são aprisionadas pela própria imagem em avanço contínuo sobre si mesmas.

1 Assisti ao espetáculo duas vezes. A primeira, logo que estreou no Centro Cultural Municipal Sérgio Porto, no Rio de Janeiro e, a segunda vez, no CentQuatre, em Paris. Nesta última, toda a equipe era visível por detrás do espelho, o que propositalmente, no processo de recepção, favoreceu a consciência da dimensão híbrida do trabalho. 


\section{0 ator $\mathrm{e} O$ ato de "fabricar imagens"}

Aqui me interessa analisar de que modo o ator se relaciona com o duplo de si projetado - questão recorrente em diversos espetáculos contemporâneos. Parto da hipótese de que, ao criar e se relacionar com imagens de si, do outro e/ou imagens da cena, por meio do uso da câmera, o ator se transforma em interactor. $O$ processo em tempo real de captação e projeção de imagens dilui as fronteiras entre o tempo passado (o que seria da ordem de um pré-registro) e o presente, complexificando a interação entre um corpo que se expõe para o dispositivo e um corpo-imagem produzido por ele. Pode-se dizer que, nesse caso, o hiato, o intervalo mínimo entre um e outro, é sustentado tão somente pela presença do ator, bem como pelas suas ações que intermediam o ato de exposição para o dispositivo-câmera e a imagem criada. Há, nesse sentido, ações que correspondem a um "fabricar-imagens"; são elas que configuram e legitimam um estado intermediário de exposição do dispositivo. É como se o ator dissesse: este sou eu, este é o dispositivo e esta é a imagem criada. Entre mim, o dispositivo e a imagem existe um processo que agora revelo. Veja como fabrico um outro de mim! Ou, ainda: veja como crio imagens de outros! A fabricação de imagens de si e do outro pressupõe uma interação entre $o$ ator e a imagem projetada, por meio de um ato consciente que se inicia na captação da imagem de si e/ou do outro e se conclui no reconhecimento da imagem produzida. É preciso, de algum modo, revelar o próprio ato de criação da imagem.

É evidente que nem sempre é possível visualizar esse processo de fabricação da imagem pelo ator. Em muitos casos, a imagem intermedial é produzida de modo indireto, como nos espetáculos Rouge Decanté, de Cassiers, E se elas fossem para Moscou?, de Christiane Jatahy, entre muitos outros. No primeiro, as imagens, projetadas em telas diferentes, não são criadas, tampouco manipuladas pelo ator. No segundo, apesar de os atores de Jatahy produzirem imagens em cena com o uso de câmeras, a sua manipulação (o tempo de exposição, a montagem das sequências e a escolha dos planos) é realizada fora da cena, pela própria diretora.

A fabricação de imagens de si e do outro pressupõe uma interação entre o ator e a imagem projetada, por meio de um ato consciente que se inicia na 
captação da imagem de si e/ou do outro e se conclui no reconhecimento da imagem produzida.

\section{Imagens sensíveis em MDLSX, da companhia Motus}

O espetáculo solo MDLSX, da companhia italiana Motus, dirigido por Enrico Casagrande e Daniela Nicolò, apresenta a história de vida da atriz Silvia Calderoni. A atriz, que durante sua infância foi classificada como hermafrodita, questiona as fronteiras de sua sexualidade e a representação sociopolítica de seu corpo, fazendo uso de imagens de arquivo familiar. Calderoni atesta sua transformação por meio da "transgressão", criando "estratégias para agredir os hábitos perceptivos" de si mesma e do espectador. (CALDERONI, 2016, tradução minha).

No palco, vemos uma grande mesa com um laptop, um microfone, um aparelho de som e uma tela em formato de espelho redondo, o que provoca o reconhecimento por parte do público do caráter autoficcional da proposta. "Quem sou eu diante do espelho?" é questão norteadora do espetáculo. Existe um jogo de vai e vem entre as imagens de um passado revisitado e as imagens captadas e projetadas por meio de uma pequena câmera. Ambas configuram um movimento de desnudamento do corpo em um fluxo intenso entre a preparação da câmera, a escolha das músicas e a realização das ações. Há a preparação de uma ambiência, seja por meio de extratos de vídeos antigos, autobiográficos, referentes a imagens do passado, seja a partir da captação em tempo real das ações realizadas em cena, além da trilha musical escolhida para o que chamarei aqui de quadro narrativo, representativo de um conjunto de ações referentes a sua trajetória de vida.

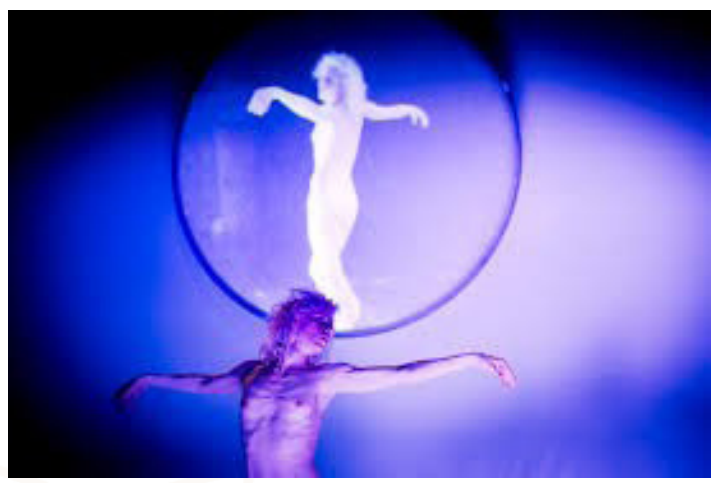

Figura 3 - Sílvia Calderoni e seu duplo projetado na tela-espelho

Foto: Simoni Stanislai 
Calderoni escolhe 24 canções dos anos 1980 e 1990 que fizeram parte de sua infância e adolescência. Em cena, ela se torna DJ e VJ, manipulando as canções e as imagens de seus arquivos pessoais. Ou seja, não há interferência externa na cena; a "fabricação de si" depende da visibilidade dos dispositivos, manipulados por ela em cena e expostos para o espectador. O encontro da atriz com seu passado é, nesse sentido, percebido como uma escolha pessoal que privilegia momentos específicos de sua vida em detrimento de outros. De vários momentos, três me parecem interessantes para entendermos como ela constrói a narrativa de si. A primeira imagem do espetáculo mostra Silvia ainda criança, com 9 ou 10 anos, cantando no palco. Vemos o primeiro desconforto com uma sexualidade normativa com a qual ela não se identificava na infância. Em um momento posterior, outro vídeo mostra uma viagem de Silvia, na adolescência, na qual ela rompe definitivamente com a imagem cristalizada de um corpo feminino e, pela primeira vez, experimenta vestir roupas masculinas, cortando o cabelo e adotando um outro jeito de falar, andar, sentar, enfim, de se expressar. Um último vídeo (emocionante) mostra o reencontro com seu pai após assumir para o mundo uma sexualidade livre e o questionamento radical do gênero a ser adotado. No encontro, pai e filha dançam freneticamente.

Escolhi esses três momentos por julgá-los decisivos na dramaturgia autoficcional do espetáculo, pois revelam o percurso de transformação e aceitação do corpo diante de si e do outro (espectador). É importante frisar que Calderoni não permanece inerte diante dos vídeos. Ela não ocupa um lugar de espectadora de si, apesar de olhar para as imagens em um processo de autorreconhecimento, fundamental (como falei anteriormente) para a consciência do ato de fabricação de si. Ao expor tais vídeos e fotos, ela narra, dança e efetua ações que transformam, no espaço da cena, seu corpo híbrido. E filma essas mesmas ações que são igualmente projetadas na cena. Filma seu corpo que se constrói e desconstrói, alternando a projeção de tais imagens com as de seu arquivo pessoal, que são tradutoras de seu sentimento de não pertencimento. Movimentos angustiantes de um corpo híbrido - nem sereia, nem medusa, nem animal, nem planta (todas imagens provenientes de ações de Calderoni) - em busca de liberdade. Corpo que questiona a todo tempo: homem ou mulher, isso é importante? Calderoni utiliza ainda trechos do 
romance Middlesex, de Jeffrey Eugeneides, além de análises teóricas sobre gênero, como o Manifesto contrassexual, de Paul Preciado, que investe em uma teoria do corpo como estratégia de resistência ao poder heteronormativo e limitador. Calliope Stephanides, personagem de Middlesex, é considerada hermafrodita; nasceu menina e, durante sua adolescência, torna-se menino. Sua sexualidade foi objeto de um livro de medicina sobre doenças raras, e seu sexo classificado como indeterminado.

Ao analisar as possibilidades de narração autobiográfica, reflito sobre o fracasso do sujeito diante de uma imagem parcialmente opaca, uma imagem que não é senão construção/criação, uma imagem fabular de si porque, apesar de tudo desejar apreender, muito Ihe escapa, já que, como afirma Judith Butler (2015, p. 54), "as histórias não captam o corpo a que se referem." A história de um corpo não é totalmente narrável. De certa forma, ser um corpo é o mesmo que ser privado de uma recordação completa da própria vida. "Meu corpo tem uma história da qual não posso ter recordações", afirma Butler (2015, p. 54). As imagens de MDLSX são utilizadas a fim de recuperar essa memória do corpo, são espécies de mosaicos que apresentam peças lacunares, apontando para a falta que constitui em si mesma a singularidade de um corpo avesso às classificações, um corpo contando "uma história que estabelece uma opacidade parcial" consigo mesmo (BUTLER, 2015, p. 54).

Diante da exposição de imagens de si fabricadas e projetadas em uma tela-espelho por Calderoni, retomo a comunicação de Lacan (1966) sobre o estágio do espelho na formação do eu e, posteriormente, a discussão apreendida pela psicanalista François Dolto (1984), que afirma que a imagem inconsciente do corpo não se remete apenas ao estágio do espelho, mas o antecede e continua a habitar o sujeito por toda a sua vida. A imagem inconsciente do corpo vai permitir ao sujeito sua articulação com as imagens essenciais à sua construção. Tomando essa ideia por base, reflito nesta pesquisa sobre a categoria de imagem sensível (COCCIA, 2013) e sua relação com o espelho como metáfora. Esse espelho aponta para o excesso de imagens produzidas na contemporaneidade, para a relação conturbada do sujeito com o objeto espeIho e, também, para a análise do espelho (neste caso, do espelho-tela) como objeto. A imagem sensível ocupa exatamente um entre-lugar, não pertencendo 
nem às coisas, nem aos sujeitos (como uma imagem de um objeto em um espelho é separada do objeto que perdura no espelho mesmo quando ninguém a olha).

\begin{abstract}
A experiência do espelho é a de um desdobramento, da constituição de duas esferas geneticamente separadas: de uma parte, a esfera na qual o eu-sujeito e o eu-objeto existem, a carne e o espírito, a matéria e a inteligência que coincidem perfeitamente; de outra, a esfera das imagens que é separada como se estivesse exilada do corpo e da alma em uma mesma intensidade. (Ibid., p. 30, tradução minha)
\end{abstract}

Coccia retoma a concepção aristotélica de que o sensível é sempre alguma coisa exterior ao indivíduo e às coisas. A imagem projetada em um espelho - e aqui interessa a investigação da superfície de projeção especular em MDLSX - existe apartada do sujeito, como se ocupasse um outro lugar. Nesse sentido, o espelho multiplica as imagens de si, uma vez que há uma separação entre sujeito e objeto, entre o que se vê no espelho e a imagem idealizada de si. Para Coccia (Ibid., p. 54, tradução minha), a trágica separação provoca um tornar-se imagem, "um exercício de deslocamento, um exercício de multiplicação de si'. Diante da permanência das imagens que multiplicam, deformam, prolongam, dividem e ampliam o corpo de Calderoni (na minha retina até hoje), levanto duas possibilidades de interação do ator com sua imagem ao refletir sobre o corpo como categoria de análise:

- um corpo-imagem (inseparável da imagem projetada), constituindo um só corpo. Nesse sentido, o corpo é suporte e suporta a imagem. É um corpo-tela. Transpassado pela imagem, é superfície de projeção e, ao mesmo tempo, é transformado pela interferência direta da imagem sobre a pele. Trata-se de um corpo que perde sua estrutura, dando lugar a uma síntese orgânico-maquinal. Para o ator, é necessário a percepção de um corpo outro; nem carne, nem imagem, o que modifica a forma de interação com o espaço, com o tempo de exposição da imagem;

- o corpo que intervém na imagem, desconstruindo e reconstruindo o quadro apresentado anteriormente. A imagem projetada na cena é modificada e manipulada pela intervenção direta da ação física do ator, o que incluiu o ato de fabricar imagens de si. 
Em ambos os casos, as imagens sensíveis perduram para além de uma tentativa de apreensão. Para além do próprio corpo.

\section{Referências bibliográficas}

BUTLER, J. Relatar a si mesmo. Crítica da violência ética. Belo Horizonte: Autêntica Editora, 2015.

CHATONSKY, G. La répétition des limites. Diffusion, projection et immersion. In: POISSANT, L; TREMBLAY, P. Esthétique des arts médiatiques: proliferation des écrans/of screens. Québec: Presses de l'Université du Québec, 2008. p. 87-129.

COCCIA, E. La vie sensible. Paris: Rivage poche/Petite bibliothèque, 2013.

COUCHOT, E. Des images, du temps et des machines dans les arts et la communication. Paris: Actes Sud, 2007.

Préface. In: LEJEUNE, F. Corps-à-corps oeuvre-public: l'expérience des installations interactives. Paris: L'Harmattan, 2015. p. 7-11.

DOLTO, F. L'image inconsciente du corps. Paris: Seuil, 1984.

LACAN, J. Le stade du miroir comme formateur da la fonction du Je. In:

Écrits. Paris: Seuil, 1966

MANOVICH, L. Le langage des nouveaux médias. Paris: Les presses du réel, 2010.

MARLEAU, D. Une fantasmagorie technologique. Entretien avec Denis Marleau réalisé par Louise Ismert. Catalogue du Musée d'Art Contemporain de Montréal, 2002, p.5-6.

Introductions et entretiens. In: PROUST, S. Denis Marleau. Arles: Actes Sud papiers, 2010.

WEBER, P. Le corps à l'épreuve de l'installation-projection. Paris: L'Harmattan, 2003.

Recebido em 07/11/2017

Aprovado em 09/05/2018

Publicado em 29/06/2018 